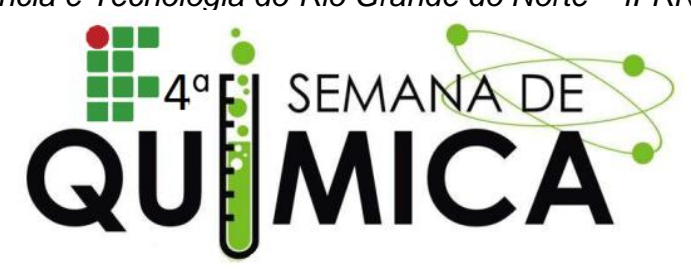

\title{
ESTUDO TEÓRICO DA ESTABILIDADE DE CICLOALCANOS VIA TEORIA G3
}

LINS, M. C. (IFRN/NC); SOUSA, S. C. O. (IFRN/NC); LEAL, R. C. (IFRN/NC)

Palavras Chave: Estabilidade, Cicloalcanos, Teoria G3.

\section{INTRODUÇÃO}

Os cicloalcanos são hidrocarbonetos cíclicos saturados com diversas aplicações industriais, principalmente na área petrolífera. Sabe-se que a geometria do sistema pode interferir na estabilidade do anel a partir da tensão provocada pela modificação dos ângulos entre as ligações. Para o químico alemão Adolf von Baeyer, estruturas como as do ciclopropano e ciclobutano sofrem o que é conhecido como tensão angular que potencializa o rompimento da ligação. De acordo com ele o ciclopentano deve ser o cicloalcano mais estável devido à proximidade com o ângulo de $109,5^{\circ}$. Assim, anéis de cinco e seis membros tornam-se mais estáveis devido a maior proximidade com a angulação de $109,5^{\circ}{ }^{1}$

O objetivo deste trabalho é estudar a estabilidade de uma série de cicloalcanos utilizando a teoria $\mathrm{G} 3$, que possui elevado grau de precisão $( \pm 2 \mathrm{kcal} / \mathrm{mol})$ na estimativa de propriedades termoquímicas variadas.

\section{METODOLOGIA}

Todos os cálculos foram executados através do software Gaussian 09W. Utilizou-se a teoria G3 ${ }^{2}$ para obtenção da energia total (Eq. 1) de uma série de cicloalcanos, contendo 3 a 8 átomos de $C$.

$\mathrm{E}_{\mathrm{G3}}=\mathrm{E}[\mathrm{MP} 4 / 6-31 \mathrm{G}(\mathrm{d})]+\Delta \mathrm{E}_{(+)}+\Delta \mathrm{E}_{(2 d f, p)}+$ Eq.

$\Delta \mathrm{E}_{(\mathrm{QCl})}+\Delta \mathrm{E}_{(\mathrm{G} 3 / \text { arge })}+\Delta \mathrm{E}_{\mathrm{SO}}+\Delta \mathrm{E}_{\mathrm{HLC}}+\mathrm{E}_{\mathrm{ZPE}}$

onde a energia de referência $E[M P 4 / 6-31 G(d)]$ é melhorada pelas seguintes correções: uma correção de funções difusas, $\Delta \mathrm{E}_{(+)}$; uma correção de funções de polarização mais elevadas em átomos diferentes de hidrogênio e funções $p$ em hidrogênios, $\Delta \mathrm{E}_{(2 d f, p)}$; uma correção para efeitos de correlação usando o método de interação de configuração quadrática, $\Delta \mathrm{E}_{(\mathrm{QCl})}$; uma correção para efeitos de conjunto de base, $\Delta \mathrm{E}_{(\mathrm{G} 3 / \text { arge })}$; uma correção de spin-órbita somente para espécies atômicas, $\Delta \mathrm{E}_{\mathrm{so}}$; uma correção empírica de alto nível, $\Delta \mathrm{E}_{\mathrm{HLC}}$; uma correção térmica obtida pelo escalonamento das frequências a partir da energia do ponto zero, E EPE.

\section{RESULTADOS E DISCUSSÕES}

A Tabela 1 mostra a estabilização da série de cicloalcanos analisados à medida que o número de grupos $-\mathrm{CH}_{2}$ aumenta. Os cicloalcanos de 3 e 4C são menos estáveis, devido uma forte tensão angular o que causa uma certa instabilidade no anel, como já era esperado. Os cicloalcanos de ordem superior a $5 \mathrm{C}$ continuam a sofrer uma forte estabilização, apesar do valor médio de ângulo de ligação permanecer praticamente constante.

Tabela 1 - Energia relativa $(\Delta E)$ em $\mathrm{kcal} \mathrm{mol}^{-1}$ e ângulo médio $\left({ }^{\circ}\right)$ obtidos via teoria $\mathrm{G} 3$

\begin{tabular}{|c|c|c|c|}
\hline \multirow[b]{2}{*}{ Cicloalcanos } & \multicolumn{3}{|c|}{ teoria G3 } \\
\hline & u.a. & $\begin{array}{c}\Delta \mathrm{E} \\
{\left[\mathrm{kcal} . \mathrm{mol}^{-1}\right]}\end{array}$ & $\begin{array}{l}\text { Ângulo } \\
<\text { C-C-C }\end{array}$ \\
\hline Ciclopropano & $-117,76419$ & $49.305,18$ & $60^{\circ}$ \\
\hline Ciclobutano & $-157,03723$ & $24.660,98$ & $87,9^{\circ}$ \\
\hline Ciclopentano & $-196,33700$ & 0 & $104,3^{\circ}$ \\
\hline Ciclo-hexano & $-235,61693$ & $-24.648,53$ & $111,1^{\circ}$ \\
\hline Ciclo-heptano & $-274,87645$ & $-49.284,25$ & $115,3^{\circ}$ \\
\hline Ciclooctano & $-314,16532$ & $-73.938,39$ & $116,2^{\circ}$ \\
\hline
\end{tabular}

\section{CONCLUSÃO}

Ao contrário do que pensava A. Baeyer, cicloalcanos de ordem superior a $5 \mathrm{C}$ continuam a estabilizar-se. A análise de decomposição de energia pode revelar outros fatores contribuintes, além da tensão anelar. Cálculos envolvendo cicloalcanos de ordem superior encontram-se em andamento.

\section{REFERÊNCIAS}

${ }^{1}$ CAREY, F. A. Química Orgánica. - Ciudad del Mexico: McGraw-Hill Interamericana, 2006.

${ }^{2}$ CURTISS, L. A.; Raghavachari, K.; Redfern, P.C.; Rassolov, V.; Pople, J. A. Journal of Chemical Physics 109, 7764, 1998. 